\title{
Values for and Tolerance towards Elephants (Elephas maximus maximus) In and Around Victoria-Randenigala-Rantambe Sanctuary
}

\author{
M.G.C. Sooriyabandara \\ Department of Wildlife Conservation, Battaramulla, Sri Lanka \\ csooriyabandara@gmail.com
}

\begin{abstract}
Human-wild elephant conflict poses a great challenge to wildlife managers, conservationists and local people. This conflict occurs where elephants and humans utilise the same habitat. In order to address this conflict it is critical to understand local people's value and tolerance level for the wild elephants. In this study local people's perceptions and beliefs about elephants are presented. The analysis was based on household survey assessing human perceptions of elephant conservation issues in and around Victoria-Randenigala-Rantambe Sanctuary. Structured interviews were conducted during the period of February to August, 2014. During that period, 345 households were interviewed. PASW statistics 18 software was used to run a Principle Component Analysis (PCA) with varimax rotation separately with 09 value and 11 tolerance statements. One way Analysis of Variance (ANOVA) was used to compare mean value and tolerance differences across independent variables. Results showed that local people highly value but have moderate tolerance for elephants. Higher values and tolerance for elephants were significantly influenced by household wealth and length of residency. Furthermore, high resource-use and living close to the forest resulted in lower values and tolerance levels for elephants. Conservation education, improved compensation programmes and participatory approaches are suggested as techniques that could increase tolerance levels for elephants.
\end{abstract}

Keywords: Human-wild elephant conflict, Tolerance, Principle Component Analysis 